1 Prefeitura Municipal de Belo Horizonte - Belo Horizonte (MG), Brasil. Orcid: https://orcid. org/0000-0001-73864377

lidianevieira@pbh.gov.br

2 Universidade Federal de Minas Gerais (UFMG),

Faculdade de Medicina,

Departamento de

Medicina Preventiva

e Social (MPS) - Belo

Horizonte (MG), Brasil.

Orcid: https://orcid.

org/0000-0002-2240-

6146

soraya@nescon.medicina.

ufmg.br

\section{Intersetorialidade na promoção da saúde escolar: um estudo do Programa Saúde na Escola}

\author{
Intersectoriality in the promotion of school in health: a study of the \\ Health in School Program
}

Lidiane Sales Vieira1, Soraya Almeida Belisário²

DOI: 10.1590/0103-11042018S409

RESUMO Esta pesquisa teve por objetivo analisar o Programa Saúde na Escola no distrito sanitário de uma das capitais brasileiras sob a ótica da intersetorialidade nas ações de promoção da saúde escolar. Trata-se de pesquisa qualitativa e exploratória baseada em estudo de caso que utilizou a análise documental como fonte de coleta de dados. Os resultados revelaram que na integração entre os setores ainda acontecem ações pontuais e abordagens fragmentadas, mas que aos poucos emergem propostas articuladas e comprometidas com a intersetorialidade e promoção de saúde. Dentre os desafios, destacam-se a necessidade de processos de monitoramento e avaliação do programa no âmbito da promoção de saúde e a inserção ativa da comunidade no campo.

PALAVRAS-CHAVE Promoção da saúde. Colaboração intersetorial. Serviços de saúde escolar. Políticas públicas de saúde.

ABSTRACT This study aimed to analyze Health in School Program in the health district of one of the Brazilian capitals adopting the intersectoriality approach in the school health promotion actions. This is qualitative and exploratory research based on case study that applied documental analysis as source of data collection. Results revealed that occasional and fragmented actions still occur in the integration between sectors, but also articulated proposals gradually emerge committed to intersectoriality and health promotion. Among the challenges, we highlight the need for monitoring and evaluating the program as for health promotion as well as active community insertion in the field.

KEYWORDS Health promotion. Intersectoral collaboration. School health services. Public health policy. 


\section{Introdução}

A escola como cenário de saúde coletiva passa por potencialidades que se justificam tanto pela expressividade sociodemográfica relacionada à infância e adolescência como pelo enfrentamento estratégico de vulnerabilidades que acometem o público presente no ambiente escolar¹. Segundo a Organização Mundial da Saúde ${ }^{2}$, a abertura da escola aos propósitos de saúde como prioridade pública apoia-se na compreensão de que um programa de saúde escolar eficaz seja um dos investimentos mais promissores da nação para melhorar simultaneamente educação e saúde. Dessa forma, em todo o mundo, os problemas elencados como as principais causas de morbidade e mortalidade entre crianças e adultos podem ser prevenidos ou reduzidos com programas de saúde escolar e saúde juvenil².

Nessa perspectiva, a integração entre saúde e escola se referencia na intersetorialidade delineada com a convocação de diferentes setores para a realização conjunta de intervenções promotoras de melhores condições de vida e saúde $^{3}$. Assim sendo, a relação saúde-escola também se ancora na promoção de saúde determinada como processo de autonomia e ampliação das possibilidades de indivíduos e comunidades no controle sobre sua saúde e qualidade de vida ${ }^{4,5}$.

No Brasil, os princípios da saúde na escola foram incorporados nos projetos nacionais conforme as políticas públicas foram aproximadas do movimento global das escolas promotoras de saúde ${ }^{6}$. Nos anos 1990, houve um esforço nacional para a apropriação do conceito de escolas promotoras de saúde ${ }^{7}$ e, em 2007, os Ministérios da Saúde e Educação elaboraram e aprovaram a regulamentação do Programa Saúde na Escola (PSE) ${ }^{8}$. A publicação desse decreto representou um marco no processo de apropriação do espaço escolar como campo de saúde?

O PSE preconiza ações intersetoriais e de mobilização de parceiros na rede de atenção básica à saúde e ensino fundamental público a fim de qualificar o cuidado individual e coletivo e reduzir os riscos e agravos que acometem crianças e adolescentes, ampliando mecanismos de enfrentamento e cuidado integral ${ }^{8,10}$. Desde sua institucionalização, o PSE apresentou avanços e importantes desafios, e sua agenda de adesões expandida nos marcos regulatórios ${ }^{11,12}$ também é perpassada de ações frequentemente problematizadas na perspectiva das conexões entre setores ${ }^{13}$.

Proposta ampla, que considera a comunidade na qual se insere e a sociedade na qual se estrutura, idealmente, a saúde na escola não trata de inserções avulsas e descontextualizadas, mas relaciona provisão de recursos específicos, ações continuadas e estratégias intersetoriais ${ }^{13}$. Assim, a escola é estabelecida como espaço cada vez mais envolto nos interesses políticos públicos intersetoriais aptos à promoção de saúde. Vale, para tanto, aprofundar a compreensão sobre o contexto, identificar as ações realizadas, bem como entender seus limites e possibilidades no andamento das situações vivenciadas.

Portanto, o objetivo desta pesquisa foi o de analisar o PSE local sob a ótica da intersetorialidade nas ações de promoção de saúde escolar em um distrito sanitário de uma das capitais brasileiras.

\section{Métodos}

Trata-se de pesquisa exploratória, descritiva, de abordagem qualitativa que utilizou a análise documental como fonte de coleta de dados. Utilizou-se a estratégia de estudo de caso, que possibilitou identificar as ações de promoção da saúde desenvolvidas pelo PSE em um distrito sanitário de uma das capitais brasileiras, bem como lacunas e desafios nas ações propostas ou desenvolvidas na localidade.

O contexto deste estudo foi o cenário do ensino fundamental público e da atenção básica em território com vulnerabilidades específicas, em que indicadores municipais associam o comprometimento da saúde infanto-juvenil a riscos de importância pública, desde eventos 
de violência a aspectos de acesso e qualidade de vida. O distrito sanitário desta pesquisa tem uma população superior a 260.000 habitantes, 28 escolas municipais de ensino fundamental regular e 16 Unidades Básicas de Saúde (UBS). Todas as 28 escolas e 83 Equipes de Saúde da Família (EqSF) ambientadas nas 16 UBS estão aderidas ao PSE.

Realizou-se pesquisa documental que consistiu na identificação de publicações institucionais nas secretarias regionais de saúde e educação do distrito sanitário e em consultas no Diário Oficial do Município (DOM), totalizando 209 documentos. Os materiais levantados se caracterizaram por documentos de primeira mão, que não receberam tratamento analítico ${ }^{\mathbf{1 4}}$, tais como leis, decretos, deliberações, portarias municipais, programas e planos de governo, e documentos de segunda mão, que já foram trabalhados ${ }^{14}$, como relatórios, manuais, cartilhas e atas de designações de políticas.

O período do estudo compreendeu os anos de 2008, quando o Município aderiu ao programa, a 2016, ano de realização da pesquisa. Dos 209 documentos pesquisados, 56 são referentes a publicações oficiais do Município e os demais 153 são relatórios da experiência do PSE no distrito pesquisado.
Analisou-se o material segundo a linha conceitual dos modelos teóricos de saúde na escola propostos por Silva e Bodstein ${ }^{13}$. Definiram-se os pontos principais com base nas prioridades do $\mathrm{PSE}^{8}$ confirmadas durante a leitura do material: promoção de saúde na escola, organização dos serviços, ações de mobilização e divulgação, articulação intersetorial e parcerias, segundo os modelos teóricos da saúde na escola ${ }^{13}$.

Este estudo vincula-se ao projeto 'Programa de Promoção de Saúde e Prevenção da Violência na atenção Básica de Saúde' 2012-2017 e faz parte da pesquisa intitulada 'Intersetorialidade entre políticas públicas de saúde e educação na promoção da saúde escolar', aprovada pelo Comitê de Ética na Pesquisa (CAAE 01140812.1.0000.5149).

\section{Resultados e discussão}

No total, analisaram-se 209 fontes distribuídas entre 56 documentos municipais regulatórios sobre diretrizes políticas saúde-educação e qualificação profissional e divulgação, que foram somados a 153 documentos de caráter descritivo do andamento do programa no território pesquisado (quadro 1). 
Quadro 1. Resumo da caracterização dos documentos pesquisados segundo período de publicação

\begin{tabular}{|c|c|c|c|c|c|c|}
\hline & Documer & & & & Volume & Ano-período \\
\hline & & Planos Muni & pais de Saúde & & 3 & \\
\hline & & Portarias Mc & cipais & & 4 & $2008-2016$ \\
\hline & & Relatórios A & ais de Gestão & & 9 & \\
\hline & & Relatórios fir & s de Conferências Muni & s de Saúde & 3 & 2009-2013 \\
\hline & : & Relatórios fir & s de Conferências Muni & s de Educação & 3 & 2009-2015 \\
\hline & & Programaçõ & Anuais de Saúde & & 6 & $2010-2016$ \\
\hline & 尊 & Relatórios C & selho Municipal de Educ & de Belo Horizonte & 2 & $2010-2015$ \\
\hline$\frac{\circ}{\tilde{\pi}}$ & $\begin{array}{ll}\pi & 0 \\
2 \pi & 0 \\
20 & -1\end{array}$ & Lei municipa & & & 1 & 2011 \\
\hline$\frac{\mathscr{n}}{\bar{z}}$ & 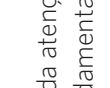 & $\begin{array}{l}\text { Relatórios de } \\
\text { Adolescente }\end{array}$ & valiação anual Conselho & nicipal Direitos da Criança e do & 3 & 2013-2015 \\
\hline$\frac{\bar{n}}{\pi \frac{2}{4}}$ &  & $\begin{array}{l}\text { Plano Munic } \\
\text { Adolescente }\end{array}$ & de Promoção, Proteçã & Defesa dos Direitos de Crianças e & 1 & 2014 \\
\hline$\sum_{5}^{5}$ & & Plano Munic & al para Infância e Adoles & & 1 & 2015 \\
\hline 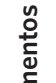 & 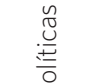 & $\begin{array}{l}\text { Relatório fin } \\
\text { te de Belo H }\end{array}$ & $\begin{array}{l}\text { Conferência municipal d } \\
\text { zonte }\end{array}$ & reitos da criança e do adolescen- & 1 & \\
\hline 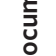 & $\frac{a}{y}$ & Deliberações & onselho Municipal Direi & da Criança e do Adolescente & 2 & 2015-2016 \\
\hline & $\stackrel{\pi}{\infty}$ & Atas de reun & es do Conselho de Alime & ção Escolar de Belo Horizonte & 3 & \\
\hline & & Decreto Mur & ipal & & 1 & 2016 \\
\hline & & Manual & & & 1 & $2009-2015$ \\
\hline & 品 & Cartilhas Mc & cipais & & 4 & \\
\hline & $\stackrel{\xi}{\xi} \frac{5}{0}$ & Informes & & & 3 & \\
\hline & & Protocolos e & uias Municipais & & 5 & \\
\hline & Documer & do Distrito & Experiências, eventos, & Relatórios distritais & 96 & $2011-2016$ \\
\hline & Sanitário & & $\begin{array}{l}\text { intervenções do PSE } \\
\text { distrital }\end{array}$ & Portfólios escolares & 57 & $2014-2016$ \\
\hline
\end{tabular}

Institucionalização do Programa Saúde na Escola no Município

No conjunto dos 56 documentos municipais, definem-se instruções sobre organização do trabalho em saúde no campo escolar, informação à comunidade sobre o PSE, regulamentações públicas via deliberações políticas e prestação de resultados gerais da saúde e educação do Município (tabela 1). 
Tabela 1. Características gerais dos documentos municipais de saúde e educação relacionados à saúde na escola

\begin{tabular}{|c|c|c|c|c|}
\hline & Normativos & Vigilância & Mobilização & \\
\hline Especificações documentais & $\begin{array}{l}\text { Resoluções } \\
\text { Municipais }\end{array}$ & $\begin{array}{r}\text { Acompanhamento de } \\
\text { resultados }\end{array}$ & $\begin{array}{r}\text { Qualificação profissional e } \\
\text { divulgação }\end{array}$ & Total \\
\hline $\begin{array}{l}\text { Leis, decretos, portarias e } \\
\text { deliberações }\end{array}$ & 8 & - & - & 8 \\
\hline Conferências Municipais & 7 & - & - & 7 \\
\hline Planos Municipais & 5 & - & - & 5 \\
\hline Programações Municipais & 9 & - & - & 9 \\
\hline Relatórios de gestão & - & 14 & - & 14 \\
\hline Publicações instrutivas & - & - & 5 & 5 \\
\hline Divulgação & - & - & 8 & 8 \\
\hline Total & 29 & 14 & 13 & 56 \\
\hline
\end{tabular}

Desde a adesão do Município ao PSE, a saúde na escola se inseriu nas pautas prioritárias do Município em diversas regulamentações. Entre 2008 e 2010, os Planos Municipais de Saúde e Programações Anuais de Saúde preconizaram metas de triagem dos estudantes para o monitoramento de ações do PSE no Município, como o número de avaliações clínicas em oftalmologia, bucal e medições de peso e altura dos estudantes. Entre 2012 e 2016, as ações de promoção da saúde escolar também se inseriram nas prioridades do Município, pleiteadas por meio de ações intersetoriais.

A ocasião do resultado coincide com o momento de mudanças nacionais iniciadas em 2012, que, a partir do estabelecimento nacional da Semana Anual de Mobilização Saúde na Escola, inauguraram um novo momento do PSE, com enfoque no incremento de ações voltadas à abordagem e mobilização da comunidade escolar ${ }^{\mathbf{1 2}}$.

Realizaram-se repasses financeiros para o PSE com montantes sempre especificados, conforme as triagens de peso e altura, avaliações oftalmológica e bucal efetuadas, não havendo especificações de custeio sobre atividades promotoras de saúde. O destaque dado às triagens clínicas anuais de saúde, oftalmológicas e nutricionais, frente à menor frequência de atividades de promoção da saúde e prevenção, também foram percebidos em estudo semelhante ${ }^{15}$. Evidências centradas em aspectos como os expostos relacionam o grau de colaboração intersetorial proposto para programas de saúde baseados na escola, em que o uso da escola como local de prestação de serviço clínico demanda nível de colaboração diferente daquele em que se propõem práticas no âmbito da promoção de saúde ${ }^{16}$.

Nos espaços colegiados, como conferências de saúde e de educação, a interação entre os referidos setores também foi considerada nas diretrizes de cuidado do Município, desde a intervenção imediata nos riscos que vulnerabilizam o público escolar - condições alimentares, violência, gravidez, sexualidade, álcool e outras drogas - à proposição do estudo do Sistema Único de Saúde e de outras políticas públicas na grade curricular das escolas municipais.

Os documentos do Município apresentaram orientações para o incremento da saúde na escola a partir de diferentes perspectivas, com algumas ênfases distintas em (1) infraestrutura: financiamento, recursos humanos, materiais, provisão e ordenamento 
de serviços; (2) articulação intersetorial e parcerias: convocação dos setores para a saúde na escola; (3) promoção e acesso de ações de saúde escolar via realização de atividades; e (4) ações de mobilização por meio de capacitação profissional e divulgação. A ocorrência dessas ênfases é ilustrada na figura 1, que agrupa o aparecimento de tais perspectivas conforme número de documentos municipais por ano.

Figura 1. Distribuição dos documentos municipais segundo as ênfases em infraestrutura, articulação intersetorial, promoção e acesso de ações de saúde escolar e ações de mobilização, 2008-2016.
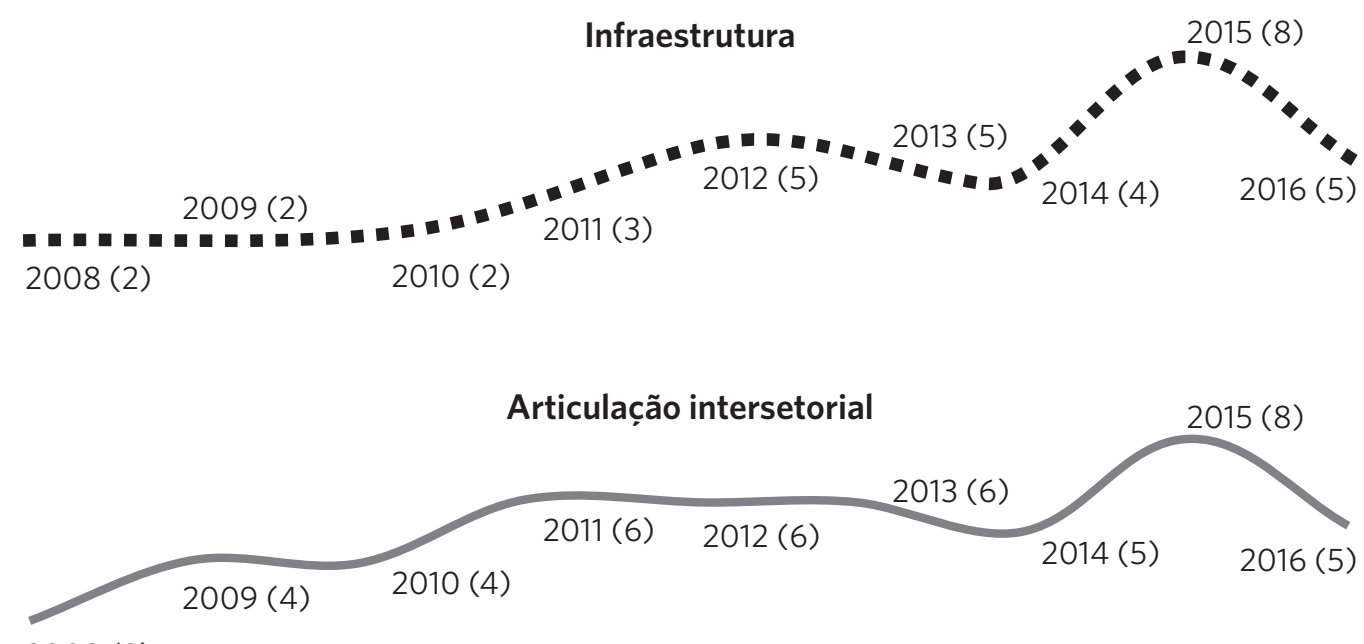

\section{Promoção e acesso de ações}

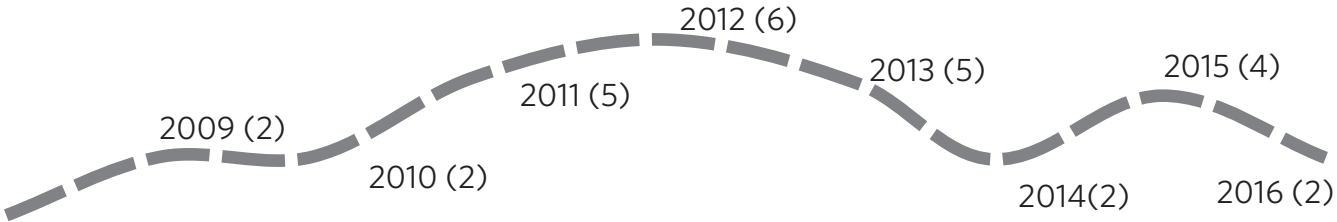

$2008(0)$

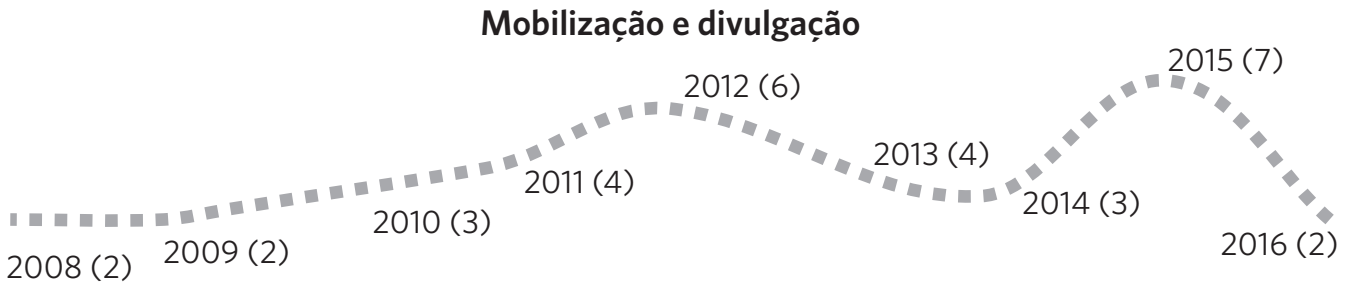


As características sobre as condições de infraestrutura acima definidas foram reportadas linearmente no período do estudo, percebendo-se a frequente ênfase no condicionamento dos atributos necessários à estruturação da saúde na escola, com maior expressividade no ano de 2015, ocasião em que foram encontrados oito documentos relacionados.

Os aspectos relacionados à articulação intersetorial estavam presentes na maioria dos documentos, superando quatro publicações ao ano a partir de 2009. Reportada como processo sistemático de articulação e organização do sistema de saúde e tendo como pressuposto a associação junto a outros setores, a intersetorialidade trata da forma de trabalhar, governar e construir políticas públicas voltadas para a promoção da saúde e melhoria da qualidade de $v$ ida $^{3}$. Imediatamente implicados na execução das ações do PSE municipal, no período de 2012 a 2016, conteúdos voltados à intersetorialidade tiveram seu ápice nos regulamentos do Município, sendo o tema abordado em seis documentos diferentes nos anos de 2011 a 2013 e em oito documentos municipais em 2015.

Relacionada à intersetorialidade, a promoção da saúde escolar gradativamente ocupou a pauta dos regimentos municipais. A partir de 2012, ano que se averigua a maior discussão sobre o tema nos regimentos do Município, quando seis documentos enfatizam a promoção de saúde na escola, passou a ser alvo de interesse nas proposições municipais.

No campo da intersetorialidade da saúde na escola municipal, foram estabelecidas diversas parcerias, em especial envolvendo as secretarias adjuntas de segurança alimentar e nutricional, saúde, transporte e trânsito, ambiente, entre outras. É possível citar intervenções contínuas e diárias referentes à saúde bucal na rotina escolar, o incremento das atividades de combate à dengue, integração crescente da Polícia Militar às escolas e inserção gradativa de parceiros como Organizações Não Governamentais e o Serviço Social do Comércio. Evidências relativamente frequentes na análise de experiências intersetoriais assinalam que o fortalecimento da relação e comunicação saúde-educação propicia que o PSE traga inovações para o campo das relações intersetoriais e da promoção de direitos de cidadania, o que expande o paradigma saúde-educação para o envolvimento de outros setores ${ }^{15,17}$.

Um balanço das ações de comunicação para a população em geral revela que foram utilizadas, em especial, formas de comunicação alternativas tais como jornal do ônibus, com destaque para materiais impressos. A exposição deu visibilidade às informações sobre promoção da saúde e prevenção de doenças e ênfase nas ações de triagens no programa. Esse achado merece considerações especiais, uma vez que o destaque dado às atividades assistenciais em pesquisas intersetoriais relaciona o grau de integração e colaboração entre os setores ${ }^{15}$ e revela o quão o modelo 'biologicista' prevalece no contexto ${ }^{14}$. $\mathrm{E}$, ainda, o fato de informes dessa natureza serem os mais divulgados à comunidade tanto fortalece o padrão tradicional de ações de saberes isolados ${ }^{\mathbf{1 4}}$ como eleva as expectativas da população por intervenções centradas em prestações clínicas ${ }^{15}$.

\section{O Programa Saúde na Escola no distrito}

Analisaram-se 153 relatórios distritais do PSE, referentes a um conjunto inteiro de documentos de segunda mão ${ }^{\mathbf{1 4}}$ centrados no enfoque informativo e composto por relatórios e portfólios distritais referentes ao universo escolar do mesmo. Os portfólios, em específico, são relatórios de autoria da educação que materializam a coletânea de ações desempenhadas pela saúde-educação local nas escolas aderidas ao PSE.

O material pesquisado no distrito sanitário é esquematicamente resumido na figura 2, segundo características e conteúdos. 
Figura 2. Caracterização dos documentos distritais

\begin{tabular}{|c|c|c|c|}
\hline \multicolumn{4}{|c|}{ Documentos distritais } \\
\hline Documentos & Definições & Natureza dos conteúdos & Setores e equipamentos envolvidos \\
\hline $\begin{array}{l}\text { Relatórios } \\
\text { distritais }\end{array}$ & $\begin{array}{l}\text { Exposição escrita das } \\
\text { experiências, eventos, } \\
\text { intervenções, aconteci- } \\
\text { mentos, fatos relativos ao }\end{array}$ & $\begin{array}{l}\text { Apurações de triagens do } \\
\text { PSE quanto a dados oftal- } \\
\text { mológicos, odontológicos e } \\
\text { antropométricos. }\end{array}$ & Saúde e Educação. \\
\hline & $\begin{array}{l}\text { PSE circunstanciado no } \\
\text { distrito. }\end{array}$ & $\begin{array}{l}\text { Atividades de promoção de } \\
\text { saúde quanto a interven- } \\
\text { ções escolares de temáticas } \\
\text { e conduções variadas. }\end{array}$ & $\begin{array}{l}\text { Saúde, Educação, Secretarias adjuntas de } \\
\text { segurança alimentar e nutricional, trânsito, } \\
\text { Polícia Militar, Organizações não gover- } \\
\text { namentais, Serviço Social do Comércio, }\end{array}$ \\
\hline Portfólios do & Coleção de trabalhos já & Apurações e atividades de & particulares, Câmara Municipal, Compa- \\
\hline PSE & $\begin{array}{l}\text { realizados num determi- } \\
\text { nado período em uma es- } \\
\text { cola. Armazena informa- } \\
\text { ções sobre os processos } \\
\text { de trabalho acontecidos } \\
\text { em cada escola partici- } \\
\text { pante do PSE. }\end{array}$ & $\begin{array}{l}\text { promoção de saúde quanto } \\
\text { à coexistência de triagens } \\
\text { e experiências promotoras } \\
\text { de saúde. }\end{array}$ & $\begin{array}{l}\text { nhia de Saneamento, Centro de Referência } \\
\text { da Assistência Social, Ministério Público, } \\
\text { Empresa de Assistência Técnica e Extensão } \\
\text { Rural, Guarda Municipal, Corpo de Bombei- } \\
\text { ros Militar, Cruz Vermelha Brasileira, Defesa } \\
\text { Civil, Serviço Nacional de Aprendizagem } \\
\text { Comercial. }\end{array}$ \\
\hline
\end{tabular}

Temas abordados e coexistentes nos 153 documentos distritais

Higiene
Vacinação
Saúde bucal

Do conjunto de 153 documentos, mais da metade foi formulada pelo setor da saúde por profissionais vinculados à secretaria distrital, enquanto, nas proposições municipais, mais de um terço foi preparado em comum acordo pelos setores da saúde e educação. No distrito, houve apenas uma elaboração de autoria compartilhada. Os detalhes da elaboração dos documentos pesquisados levantaram indícios de fragilidades locais do trabalho intersetorial relacionadas a ações específicas e desagregadas da saúde ou da educação. Como Farias et al. ${ }^{18}$, entende-se que a possibilidade de formar um espaço integrado e participativo sob a perspectiva da promoção de saúde escolar é fundamental, ainda que repleta de entraves.

Os documentos trazem dados e pontos sobre promoção e acesso de ações e assistência de saúde, associados a elementos estatísticos e a resultados ou experiências vividos na realidade local. Desse balanço, cerca de metade dos documentos relatou, de alguma forma, atividades promotoras de saúde relacionadas ao PSE local, cabendo à parte restante apurações quantitativas contendo consolidados sobre avaliações antropométricas, triagens 
odontológicas e oftalmológicas e compilados a título de prestação de contas municipais.

Para o andamento das ações localizadas no PSE no distrito, verificaram-se também os aspectos já pesquisados no âmbito municipal, em especial os conteúdos referentes à promoção da saúde e intersetorialidade. Seguindo o conhecimento de outros autores que concluíram ser a intersetorialidade uma forma de gestão possível e eficiente, mesmo frequentemente associada a dificuldades ${ }^{\mathbf{1 8}}$, no estudo local, foram averiguadas algumas ênfases em tal perspectiva. Alguns resultados evidenciaram que o processo pode reorientar o rumo à integração entre setores, dado que, em muitas experiências, percebeu-se que o compromisso do envolvimento intersetorial foi além do encaminhamento das demandas aos setores alheios e subordinação entre setores ${ }^{13}$.

Dentre os principais resultados, visualiza-se o ingresso de abordagens de saúde nas disciplinas regulares conduzidas na rede pública, como é o caso da alimentação saudável, tratada dentre os conteúdos das matérias de ciências bem como no aprendizado da matemática e de mecanismos de combate à dengue, inseridos na disciplina de português. Todas essas estratégias foram esboçadas pelo próprio corpo docente em preocupação com a saúde escolar, tanto que houve quinze ações executadas por professores em parceria ao PSE em 2014, número esse que sobe para 70 em 2015 e para 102 atividades para o mesmo universo no âmbito da saúde na escola em 2016.

Verificou-se o envolvimento dos profissionais da cantina, da limpeza, biblioteca, informática e funcionários da manutenção escolar. As palestras, gincanas, atividades de leitura, desenho e redação, bem como as artísticas, materializaram o empenho por ambientes e comunidades mais saudáveis, condizendo, assim, com a constatação já identificada em outros estudos da intersetorialidade no PSE, que destacaram a tentativa de consolidação de práticas intersetoriais, mesmo que principiadas por ações pontuais ${ }^{18}$.

Dias et al. ${ }^{19}$ confirmam, inclusive, que investimentos dessa natureza, ainda que incipientes, demonstram a orientação por objetivos em comum e a oportunidade de confiança na capacidade dos outros em assumir responsabilidades no que se refere à saúde na escola, sem obrigatoriamente ser um profissional da área da saúde.

Procurou-se identificar outros interlocutores, além da saúde e educação, que se envolveram intersetorialmente nas ações do PSE territorial. Diferentemente do achado no estudo de Farias et al. ${ }^{\mathbf{1 8}}$, observou-se que há muitas outras parcerias além da saúde e educação acessíveis ao PSE da localidade. Contudo, não se percebe a existência de envolvimento da comunidade com o programa, de forma que os sujeitos do território escolar foram reportados apenas quando da abertura da escola para eventos destinados aos pais, como feiras de cultura, ciências ou festas da família, em que também se processariam práticas do PSE. Dessa forma, é indispensável uma ação mais articulada no que tange ao envolvimento contínuo da comunidade, visto que a população do território faz jus a tal inclusão, porque, além de ser integrante cotidiana e inerente da escola, seu envolvimento é essencial para a construção da promoção de saúde nesse campo,19.

As temáticas enfatizadas nas dimensões de promoção da saúde e prevenção de agravos, regulamentadas no decreto do $\mathrm{PSE}^{\mathbf{8}}$, acontecem no contexto local (figura 2) e são acrescidas de outras sucedidas distritalmente, como as relativas à saúde emocional, consciência cidadã e política, enfocadas na adoção de animais abandonados, doação de sangue e o projeto da Câmara Mirim. As temáticas foram inovações distritais, que, dado o caráter incipiente, não estão detalhadas na figura 2, mas merecem a menção, visto que, diferentemente das críticas relatadas na literatura ${ }^{20}$, sua ocorrência mostra o movimento local em prol do reconhecimento das demandas próprias do território e, consequente, o empenho em práticas singulares.

Como importantes desafios, destaca-se a ausência de mecanismos para a produção de indicadores e processos de 
monitoramento e avaliação local da saúde escolar. Diferentemente do que acontece no âmbito municipal, no distrito não se sistematizam os dados advindos do PSE em prol de planejamentos estatisticamente fundamentados. Essa inexistência pode favorecer achados tais como os evidenciados em estudo ${ }^{15}$ que dirigiu seu enfoque às percepções de gestores, concluindo pelo baixo domínio das práticas e atuação do PSE sobre os territórios. Tendo em vista que a comunicação formal e clara levantada em outras percepções ${ }^{16}$ se opera por meio de indicadores e mensurações fundamentados, a falta dessas comunicações, alinhadas tanto nos níveis gestores como em nível de execução, podem levar à incerteza e comprometer a visão do programa.

\section{Interações entre os setores saúde e educação no fomento da promoção de saúde escolar}

O alcance e propósito dos regulamentos municipais envolveram distintos aspectos intersetoriais, interpretados com base em modelos teóricos de saúde na escola, segundo estudo de Silva e Bodstein ${ }^{13}$. Nos documentos municipais, coexistem esforços, de um lado, pela construção de ambientes de saúde em sintonia com os princípios da promoção da saúde e, de outro, por estabelecimentos disciplinares de hábitos de combate a agravos e adoecimentos. A maioria dos documentos de alcance municipal trouxe aspectos voltados à promoção de saúde, embora também revelasse, frequentemente, a convocação de hábitos individuais e biomédicos.

Todavia, quando se compara à evolução do distrito estudado, observa-se uma diferença substancial entre o que é regulado municipalmente e o que, de fato, se executa no território junto à comunidade escolar. A ocorrência coincide com constatações em diferentes territórios ${ }^{\mathbf{1 5}, \mathbf{1 7}}$, percebidas como parcerias restritas à abordagem do problema e execução unilateral de ações, o que significa que a busca de outros setores para ingresso no território escolar não é precedida ou determinada por planos e construções intersetoriais, tampouco centrada na promoção de saúde.

A prevalência de características desintegradas no distrito expõe o dilema de se operar uma política necessariamente promotora de saúde frente à ênfase de normativas limitadas e prescritivas. De fato, dificuldades semelhantes são notadas no cenário nacional, onde, mesmo frente ao conhecimento da intersetorialidade como prática estabelecida entre saúde e educação, distinguida como pilar da promoção da saúde no PSE, ela ainda não é tão estimulada em razão de entraves do cotidiano entre os setores. Há uma tentativa de consolidação de práticas intersetoriais que, na maioria das vezes, são substituídas por ações pontuais ${ }^{\mathbf{1 8}}$. Essas considerações se confirmam com a posse dos dados do distrito sanitário estudado, os quais, em diversas ocasiões, concentraram abordagens temporárias no que tange a ações de higienização e escovação, divulgação de campanhas tais como o combate a dengue, alimentação saudável, desperdício de água e práticas de atividades físicas. Muitos relatórios locais acabam, assim, por confirmar os impasses do discurso político sem a operacionalização da promoção da saúde escolar ${ }^{18}$.

Em mais de uma situação, embora o Município pregue a intersetorialidade e promoção da saúde como ênfases da abordagem escolar, suas deliberações convencionavam a prescrição de ações fragmentadas, como as praticadas no território da pesquisa. Há ocasiões em que a escola é proposta como meio cumpridor de tarefas, seja para veiculação de espetáculos, palestras de combate a endemias e campanhas sazonais ou apenas como aparato concessor do espaço físico para instalação de outros equipamentos de saúde.

Estudo $^{15}$ do PSE no Município também enfatizou potencialidades da ação intersetorial em textos oficiais sem repercussões nas práticas dos territórios em decorrência da falta de coesão que precede à ação intersetorial.

A análise documental atestou que nos registros políticos que regulam e anunciam o PSE também existe a subordinação entre setores 
e a desconsideração da perspectiva da saúde como conceito ampliado 4 . De modo geral, a presença de questões escolares pautadas na medicalização e uso unilateral da escola, caracterizadas como subordinação de setores, foram dimensões presentes e equiparáveis em cerca de um quarto dos regimentos municipais. Essa perspectiva oscilou com picos em 2009, 2012 e 2015 - justamente o período de maior movimentação das discussões políticas locais, como conferências municipais da educação, saúde e dos direitos da criança e adolescente.

Esses achados são corroborados por outro estudo que destacou o quão complexo é para a promoção da saúde se constituir, de fato, em elemento central do PSE. Ao menos no que se refere à nova forma de pensar a saúde escolar, cuja ênfase está em fatores de ordem contextual em detrimento dos fatores comportamentais, superando planejamentos estritamente assistencialistas que confundem promoção de saúde com ações comportamentais, curativas ou de prevenção ${ }^{20}$.

Município e distrito vivem momentos diferentes. Enquanto os marcos regulatórios da saúde na escola sejam ainda oscilantes, as práticas no território distrital se distanciam das premissas do compartilhamento, parceria e poder harmonicamente distribuído entre saúde e educação na promoção de saúde escolar. Percebe-se que a experiência do território local acentua o tom da perspectiva de execução e fragmentação da promoção de saúde no espaço escolar, condição presente em quase todos os documentos pesquisados. Diferentemente do que se preconizou em nível municipal, coexistem, no distrito, componentes relacionados aos mecanismos de relação verticalizada entre os setores, segundo relação ainda pautada na subordinação.

A permanência da atuação isolada foi encontrada também na análise de experiência municipal $^{15}$, evidenciada na prevalência do modelo 'biologicista'. Porém, desafios dessa ordem são passíveis de resolução conforme empreendimento qualificado, que, por sua vez, depende de sólida comunicação e relações interprofissionais ${ }^{16}$.
Sobre a elaboração da escola como elemento de encaminhamento médico, em que questões escolares são situadas no campo biológico com ênfase no redirecionamento aos serviços de saúde ${ }^{\mathbf{1 3}}$, verificou-se que, enquanto essa é uma dimensão em decréscimo nas proposições do Município, a condição perdura no distrito. Nos documentos pesquisados, a dimensão da medicalização de questões escolares se faz presente; especificamente nos anos de 2013 a 2016, a condição não oscilou e ocorreu em cerca de um quarto dos documentos distritais. Todavia, o fato dessa condição não predominar mostra fato interessante, uma vez que, sendo assim, a maioria não se dedica à medicalização, podendo também constituir indicativo de priorização de ações mais voltadas à promoção de saúde.

Entendido que a intersetorialidade implica articulação estratégica voltada à convergência de iniciativas e integração de objetivos ${ }^{\mathbf{2}, 21}$, a realidade do distrito evidencia a fragilidade já estudada por Magalhães ${ }^{22}$, quando se constatou que, apesar da intersetorialidade ser valorizada no plano normativo, ações isoladas, superpostas e descontínuas são frequentes nos territórios onde opera o PSE. No distrito, algumas das práticas do PSE se processam baseadas numa relação de independência da escola frente ao setor da saúde, repassando demandas ou abrindo suas portas para ações pontuais. Mas a existência da dimensão da medicalização de questões escolares, demonstrada em um quarto dos documentos, não pode ofuscar os demais direcionamentos que se voltam à promoção de saúde. Afinal, não se trata de abolir a existência de mecanismos clínico-assistenciais na interação saúde-escola, mas de incrementar e reconstruir as possibilidades que partem dessa demanda, tornando os setores mais próximos e, principalmente, corresponsáveis no que tange à promoção da saúde escolar ${ }^{13}$.

\section{Considerações finais}

No campo da prática da saúde escolar, a ação intersetorial é imperativa, reconhecendo que o setor saúde isolado não abrange todas as 
possibilidades de resposta para a área. As ações coordenadas entre os setores saúde e educação avançam no desenho de atos que visam à melhoria da saúde, comportamentos saudáveis, passíveis de alcance da população em geral, e em especial, a públicos prioritários que frequentam as escolas e, naturalmente, se distanciam das unidades de saúde.

No contexto estudado, o PSE no Município e distrito compõe-se como uma das iniciativas para o aumento da promoção da saúde na escola, em especial, voltada ao público que frequenta o ensino fundamental. O PSE configura recurso essencial para ajudar a se atingir a meta de redução da prevalência de agravos infanto-juvenis e aumento dos índices populacionais abordados e envolvidos em estratégias formadoras de hábitos e posturas saudáveis. Todavia, são muitos os desafios para se efetivar a intersetorialidade da saúde na escola. Para que Município e distrito consigam avançar na construção interoperativa do programa, é fundamental o uso do contexto escolar como aliado à promoção de saúde. Outro ponto consiste na inserção da participação comunitária no desenvolvimento das atividades a serem propostas na localidade, que devem ser compartilhadas e construídas em conjunto com a comunidade.

No campo da articulação da promoção de saúde e das práticas intersetoriais, destaca-se a necessidade de que as ações de saúde na escola integrem uma relação horizontal, de equivalência entre saúde e educação, expandida aos demais pontos da rede de serviços, favorecendo a resolutividade das ações. A lacuna consiste na necessidade de avançar a ação intersetorial de modo a promover ações contínuas e verdadeiramente apropriadas do discurso regulatório que evoca a promoção da saúde, mas que, frequentemente, condiciona apenas à execução de ações pontuais e desarticuladas.

Destaca-se também a parceria intermediada com diversos setores e atores na complementação de ações propostas na perspectiva do PSE, tornando os envolvidos agentes efetivamente ativos no processo. Vale aos possíveis parceiros programar ações compartilhadas referentes ao campo da saúde escolar, de modo que se supere o automatismo das palestras ou ações pontuais, o que implica, além do processo de articulação, a responsabilização mútua em prol da saúde integral do público inserido no meio estudantil.

Outro desafio consiste em fazer avançar o desenvolvimento de ações de monitoramento das práticas intersetoriais, referentes à promoção de saúde escolar, a remodelação dos mecanismos de acesso às experiências praticadas e a definição de processos públicos voltados ao conhecimento e integração das abordagens exercidas no âmbito do PSE aos setores pertinentes. Dessas ações deriva a formalização de mecanismos favoráveis à comunicação entre setores em prol da formulação, implantação, acompanhamento ou avaliação conjunta de intervenções promotoras de saúde no cenário da escola. São ações que cabem a diversos setores, incluindo saúde, educação e os variados parceiros angariados ao longo da vigência do PSE no território.

Um dos limites do estudo é a análise fundamentada em revisão de documentos. Sabe-se que nem todas as experiências do território produzidas no âmbito do PSE do distrito encontram-se organizadas e acessíveis. Assim, empreendimentos locais potencialmente relevantes podem não ter feito parte do conjunto do estudo. Tomou-se como base análise orientada a partir dos temas promoção de saúde, articulação intersetorial, condições para a formação integral de educandos, dentre outros. O universo de documentos em análise é extenso e certamente cabem outros recortes na reconstrução desse percurso.

Como conclusão, em relação aos eixos aqui analisados, pode-se reconhecer o avanço da inserção da promoção da saúde na agenda do PSE, institucionalizando tendência crescente nos diversos mecanismos de abordagem escolar. Destacam-se os avanços na inserção de parcerias de promoção da saúde na rotina do PSE, condições destinadas aos setores saúde e educação para projetos de promoção da saúde escolar e progressos expressivos no incremento da saúde 
infanto-juvenil intermediada pelo sistema público de saúde e ensino. Dentre esses, listam-se a expansão do PSE municipal, o prosseguimento na avaliação dos agravos, nas parcerias e na inovação gradativa da aproximação promotora de saúde escolar, a capacitação de recursos humanos e o fomento a mobilizações múltiplas e recíprocas. Os campos da promoção de saúde escolar e da intersetorialidade estão em processo de construção, onde Município e território ainda têm caminhos a serem percorridos, porém muitos passos já estão sendo dados.

\section{Referências}

1. World Health Organization. Growing up unequal: Gender and socioeconomic differences in young people's health and well-being. Health policy for children and adolescents, $n^{\circ} 7$. Health behaviour in school-Aged children (HBSC) study: international report from the 2013/2014 survey. [internet]. 2016 [acesso em 2017 fev 11]. Disponível em: https://euro. sharefile.com/share?\#/view/sccee42340cf4a6fb.

2. World Health Organization. School and youth health. [internet] 2017 [acesso em 2017 fev 11]. Disponível em: http://www.who.int/school_youth_health/en/.

3. Brasil. Ministério da Saúde. O SUS no seu município: garantindo saúde para todos. Brasília, DF: Ministério da Saúde; 2004.

4. World Health Organization. Charter for Health Promotion. Geneva: WHO; 1986.

\section{Colaboradores}

Vieira LS contribuiu para a concepção, planejamento, análise e interpretação dos dados; elaboração do rascunho, revisão crítica do conteúdo; e participação da aprovação da versão final do manuscrito. Belisário SA contribuiu para a análise e interpretação dos dados; revisão crítica do conteúdo; e participação da aprovação da versão final do manuscrito.
5. World Health Organization. Health promotion. [internet]. [acesso em 2016 jan 6]. Disponível em: http:// www.who.int/topics/health_promotion/en/.

6. Monteiro PHN, Bizzo N. A saúde na escola: análise dos documentos de referência nos quarenta anos de obrigatoriedade dos programas de saúde, 1971-2011. Hist. cienc. saude-Manguinhos, 2015 jun; 22(2):411-27.

7. Barbieri A, Noma AK. Políticas públicas de educação e saúde na escola: apontamentos iniciais sobre o Programa Saúde na Escola (PSE). In: Anais do Seminário de Pesquisa do Projeto Pós-Graduação em Educação, [internet]. 2013 jun 2-13; Maringá, Paraná: UEM; 2013 [acesso em 2017 fev 11]. Disponível em: http://www. ppe.uem.br/publicacoes/seminario_ppe_2013.

8. Brasil. Decreto n ${ }^{\circ}$ 6.286, de 5 de dezembro de 2007. Institui o Programa Saúde na Escola - PSE, e dá outras providências. Diário Oficial da União. 5 Dez 2007. 
9. Brasil. Ministério da Saúde, Ministério da Educação. Caderno do gestor do PSE. Brasília, DF: Ministério da Saúde, Ministério da Educação; 2015.

10. Graciano AMC, Cardoso NMM, Mattos FF, et al. Promoção da Saúde na Escola: história e perspectivas. Journal of Health \& Biological Sciences, 2015 mar; 3(1):34-8.

11. Brasil. Portaria interministerial $\mathrm{MS} / \mathrm{ME} \mathrm{n}^{\circ} 1.413$, de 10 de julho de 2013. Redefine as regras e critérios para adesão ao Programa Saúde na Escola (PSE) por Estados, Distrito Federal e Municípios e dispõe sobre o respectivo incentivo financeiro para custeio de ações. Diário Oficial da União. 11 Jul 2013.

12. Brasil. Ministério da Saúde, Ministério da Educação. Passo-a-passo: adesão Semana Saúde na Escola. Brasília, DF: Ministério da Saúde, Ministério da Educação; 2013.

13. Silva CS, Bodstein RCA. A theoretical framework on intersectoral practice in school health promotion. Ciênc. Saúde Colet. [internet]. 2016 jun. [acesso em 2016 set 16]; 21(6):1777-88. Disponível em: http://www.scielo.br/pdf/csc/v2ln6/1413-8123-csc-21-06-1777.pdf.

14. Gil AC. Delineamento da Pesquisa: Pesquisa Documental. In: Gil AC. Métodos e técnica de pesquisa social. 6. ed. São Paulo: Atlas, 2008. p. 49- 59.

15. Chiari APG, Ferreira RC, Akerman M, et al. Rede intersetorial do Programa Saúde na Escola: sujeitos, percepções e práticas. Cad Saúde Pública [internet]. 2018 [acesso em 2018 set 23]; 34 (5):1-15. Disponível em: http://www.scielo.br/pdf/csp/v34n5/1678-4464csp-34-05-e00104217.pdf.

16. Tooher R, Collins J, Braunack-Mayer A, et al. Intersectoral collaboration to implement school-based health programmes: Australian perspectives, Health Promotion International [internet]. 2017 [acesso em 2018 set 23]; 32(2):312-21. Disponível em: https:// doi.org/10.1093/heapro/dav120.
17. Sousa MC, Esperidião MA, Medina MG. A intersetorialidade no Programa Saúde na Escola: avaliação do processo político-gerencial e das práticas de trabalho. Ciênc. Saúde Colet. [internet]. 2017 [acesso em 2018 set 23]; 22 (6):1781-90. Disponível em: http://www. scielo.br/pdf/csc/v22n6/1413-8123-csc-22-06-1781. pdf.

18. Farias ICV, Franco de Sá RMP, Figueiredo N, et al. Análise da Intersetorialidade no Programa Saúde na Escola. Rev. bras. educ. med., [internet]. 2016 [acesso em 2017 mar 4]; 40(2):261-7. Disponível em: http://www.scielo.br/pdf/rbem/v40n2/1981-5271rbem-40-2-0261.pdf.

19. Dias MAS, Vieira FMBR, Silva LCC, et al. Colaboração interprofissional no Projeto Saúde e Prevenção na Escola. Ciênc. Saúde Colet. [internet]. 2016 [acesso em 2017 mar 4]; 21(6):1789-98. Disponível em: http://www.scielo.br/pdf/csc/v2ln6/1413-8123csc-21-06-1789.pdf.

20. Cavalcanti PB, Lucena CMF, Lucena PLC. Programa Saúde na Escola: interpelações sobre ações de educação e saúde no Brasil. Textos \& Contextos [internet]. 2015 [acesso em 2017 mar 4]; 14(2):387-402. Disponível em: http://revistaseletronicas.pucrs.br/ojs/index.php/fass/article/viewFile/21728/13961.

21. Bernardi AP, D’ Andréa AIR, Zampirolo DA, et al. Intersetorialidade - um desafio de gestão em Saúde Pública. Sau. \& Transf. Soc. [internet]. [acesso em 2016 jan 28]; 1(1):137-4 Disponível em: http://www. redalyc.org/articulo.oa?id=265319560020.

22. Magalhães R. Constrangimentos e oportunidades para a implementação de iniciativas intersetoriais de promoção da saúde: um estudo de caso. Cad. Saúde Pública [internet]. 2015; [acesso em 2017 mar 4]; 31(7):1427-36. Disponível em: http://www.scielo.br/ pdf/csp/v31n7/0102-311X-csp-31-7-1427.pdf.

\footnotetext{
Recebido em 09/04/ 2017

Aprovado em 03/10/2018

Conflito de interesses: inexistente
}

Suporte financeiro: não houve 